\title{
Asymptomatic acute pyelonephritis as a cause of acute renal failure in the elderly
}

\author{
G. Woodrow, S. Patel, P. Berman ${ }^{1}$, A.G. Morgan and R.P. Burden \\ Departments of Renal Medicine and ${ }^{1}$ Health Care of the Elderly, City Hospital, Nottingham NG5 IPB, UK
}

\begin{abstract}
Summary: Urinary tract infections in the elderly are common, often asymptomatic and usually benign. We report three patients who presented with acute renal failure due to acute pyelonephritis in the absence of clinical findings of infection or urinary tract obstruction. Blood and urine cultures grew Escherichia coli in two of the patients and in two patients renal biopsy confirmed acute pyogenic pyelonephritis. Antimicrobial therapy and haemodialysis led to improvement, though one patient subsequently died from an unrelated cause.

We suggest that acute bacterial pyelonephritis should be considered as a cause of acute renal failure in the elderly. Clinical features of infection may be absent despite bacteraemia. Prompt diagnosis and intervention may avoid chronic renal failure in a group that has a less favourable outcome with long-term dialysis.
\end{abstract}

\section{Introduction}

Elderly patients may not exhibit the typical clinical features associated with infection. ${ }^{1}$ Urinary tract infections are common, often asymptomatic and usually benign. Occasionally, however acute renal failure (ARF) can result from acute pyelonephritis occurring in the absence of urinary tract obstruction. $^{2-6}$ We describe three elderly patients who presented with acute renal failure (ARF) without urinary symptoms or clinical findings to suggest infection, in whom investigation revealed the presence of acute pyogenic pyelonephritis.

\section{Case 1}

A 69 year old man presented with increasing shortness of breath, ankle oedema, anorexia, lethargy and vomiting but denied any urinary symptoms. His past history included hypertension and ischaemic heart disease. On examination his temperature was normal. He was jaundiced without any features of chronic liver disease or hepatomegaly. Serum urea was $53 \mathrm{mmol} / \mathrm{l}$ and creatinine $665 \mu \mathrm{mol} / \mathrm{l}$. His bilirubin was $75 \mathrm{mmol} / \mathrm{l}$ and all the liver enzymes were mildy raised. Total white cell count was $26 \times 10^{9} / 1$ with a neutrophil leucocytosis.

Correspondence: G. Woodrow, M.R.C.P.

Accepted: 25 September 1992
Urine Dipstix showed blood and protein and urine microscopy showed numerous red and white cells but no organisms and no subsequent growth (though this may have been due to a delay of 48 hours for the sample to reach the laboratory). Ultrasound showed normal kidneys, and his liver showed fatty change thought to be due to alcohol. A renal biopsy (Figure 1) showed pus within the collecting tubules suggesting acute pyelonephritis. Tubular changes were minor and consisted of proximal tubular vacuolation. He was treated with intravenous cefotaxime and intermittent haemodialysis. After a few days renal function started to improve such that he was independent of dialysis. Liver function tests also became normal suggesting that the elevation in bilirubin and liver enzymes was due to infection.

\section{Case 2}

A 78 year old woman was admitted with generalized colicky abdominal pain, diarrhoea and vomiting. She denied urinary symptoms, though had frank haematuria on one occasion after admission to hospital. She had been fit and well and her only treatment was ibuprofen for osteoarthritis. Her temperature was normal, with a normal jugular venous pressure and skin turgor. Blood pressure was $210 / 110 \mathrm{mmHg}$. A mass was felt in the right upper quadrant of her abdomen. Serum sodium 


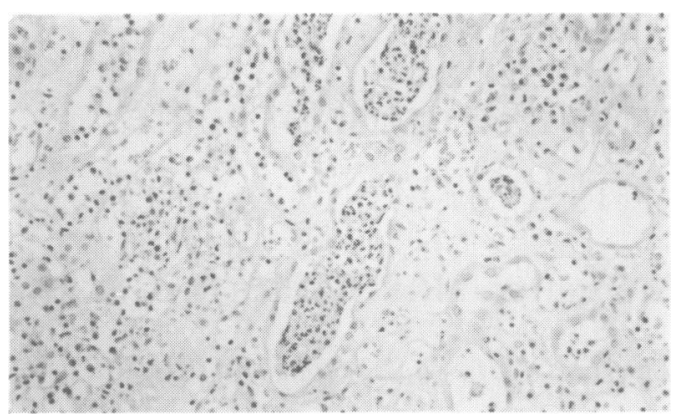

Figure 1 Renal biopsy from Case 1 showing acute pyelonephritis with distension of collecting tubules by numerous pus cells. H\&E stain. Magnification $\times 250$.

was $115 \mathrm{mmol} / 1$, potassium $6.6 \mathrm{mmol} / \mathrm{l}$, urea 45.7 $\mathrm{mmol} / \mathrm{l}$ and creatinine $761 \mu \mathrm{mol} / \mathrm{l}$. Her white cell count was $23.1 \times 10^{9} / 1$ with a neutrophil leucocytosis. Dipstix of urine showed blood and protein. Ultrasound showed that the abdominal mass was the right kidney, which was enlarged with multiple echogenic areas suggesting acute pyelonephritis and abscess formation. The left kidney was small $(6 \mathrm{~cm}$ in length). She was treated with intravenous cefotaxime and intermittent haemodialysis. Subsequent urine and blood cultures taken on admission grew Escherichia coli.

With this treatment she felt better but remained dependent on dialysis. Her progress was complicated by an episode of pseudomembranous colitis responding to oral vancomycin. Three weeks after admission she died suddenly and at post mortem the cause of death was found to be coronary artery thrombosis. Examination of her right kidney confirmed the ultrasound findings of pyelonephritis with frank pus and in addition there was papillary necrosis but no ureteric obstruction. The left kidney was small due to congenital hypoplasia.

\section{Case 3}

A 79 year old woman presented with increasing anorexia, lethargy and breathlessness. She was previously well and denied urinary symptoms. She took ketoprofen for osteoarthritis. Her temperature was normal, she was pale and mildly oedematous. There were no other abnormal findings. Serum biochemistry carried out by her general practitioner a week earlier showed a urea of $16.5 \mathrm{mmol} / 1$ and creatinine of $278 \mu \mathrm{mol} / 1$. On admission there was marked deterioration, with urea of $38.2 \mathrm{mmol} / \mathrm{l}$ and creatinine of $820 \mu \mathrm{mol} / \mathrm{l}$. Full blood count showed a haemoglobin of $8.1 \mathrm{~g} / 1$ (normochromic, normocytic) and total white cell count was $11.5 \times 10^{9} / 1$ with a neutrophil leuco- cytosis. Dipstix of urine showed blood and protein. Kidneys were normal on ultrasound. Renal biopsy showed numerous polymorphs in the tubules and interstitium, indicating acute pyelonephritis. Some glomeruli showed old organized crescents, but the main cause of her renal failure was felt to be acute pyelonephritis on a background of chronic glomerular disease. This was supported by subsequent growth of Escherichia coli from blood and urine cultures. She was treated with a prolonged course of cefotaxime and intermittent haemodialysis. Renal function has not recovered and she is dialysis dependent.

\section{Discussion}

Acute renal failure is a serious condition with an overall mortality of at least $50 \%$ in most series. The average age of patients treated for ARF has increased, ${ }^{7}$ due to more aggressive management of surgical and medical conditions in the elderly as well as increased availability of dialysis. Many ${ }^{7-9}$ but not all ${ }^{10-12}$ series show a worse prognosis in the elderly, but most survivors regain independent renal function. ${ }^{8}$ Apart from obstetric causes, the aetiology of ARF is similar in the elderly to that of young adults. ${ }^{10}$ Acute pyelonephritis is a recogo nized cause of ARF but is very unusual and may be easily missed in the elderly, ${ }^{13}$ possibly because infections may not cause typical clinical findings in this age group. ${ }^{1}$ Fever may be absent though some recent studies suggest that sublingual temperatures are unreliable in the elderly and rectal temperatures will be elevated in the majority of patients with infection. ${ }^{14,15}$

Elderly patients are more prone to urinary tract infections, the majority of cases are asymptomatic and probably benign requiring no intervention. ${ }^{16}$ Prostatic hypertrophy and possible decreased antimicrobial properties of prostatic fluid may be important for this increased incidence in men. In women there is a change in vaginal $\mathrm{pH}$, vaginal epithelial atrophy occurs, and the microbial flora changes to consist of Gram-negative organisms. Urinary tract infection is strongly correlated with dementia which may be due to faecal incontinence and perineal soiling in women, though the reason in men is unclear.

The patients we have described presented with $\tilde{O}$ acute renal failure due to acute pyelonephritis in $\omega$ the absence of urinary tract obstruction. Despite the severity of infection (and bacteraemia in two patients) all were apyrexial and had no urinary or systemic symptoms. In particular hypotension and shock were absent. Histology in two patients showed acute pyelonephritis with numerous pus cells. Acute tubular necrosis (which was a potential aetiology for ARF given the presence of bacter- 
aemia) was excluded on the basis that only minor changes in tubular morphology were present. We suggest that acute pyelonephritis should be considered as a cause of unexplained renal failure in the elderly. Careful measurement of body temperature is important and the presence of neutrophilia may

\section{References}

1. Berman, P., Hogan, B.D. \& Fox, R.A. The atypical presentation of infection in old age. Age Ageing 1987, 16: 201-207.

2. Baker, L.R.I., Cattell, W.R., Fry, I.K.F. \& Mallinson, W.J.W. Acute renal failure due to bacterial pyelonephritis. $Q$ J Med 1979, 48: 603-612.

3. Woolley, P.D., Wyman, A., Nicholls, A.J., Shortland, J.R. \& Brown, C.B. Acute renal failure due to bacterial pyelonephritis. Br J Urol 1986, 58: 733.

4. Greenhill, A.H., Norman, M.E., Cornfield, D., Chatten, J., Buck, B. \& Witzleben, C.L. Acute renal failure secondary to acute pyelonephritis. Clin Nephrol 1977, 8: 400-403.

5. Thompson, C., Verani, R., Evanhoff, G. \& Weinman, E. Suppurative bacterial pyelonephritis as a cause of acute renal failure. Am J Kidney Dis 1986, 8: 271-273.

6. Lorentz, W.B, Iskander, S., Browning, M.C. \& Renolds, G.D. Acute renal failure due to pyelonephritis. Nephron 1990, 54: $256-258$.

7. Turney, J.H., Marshall, D.H., Brownjohn, A.M., Ellis, C.M. \& Parsons, F.M. The evoluation of acute renal failure, 1956-1988. $Q J$ Med 1990, 74: 83-104.

8. Rodgers, H., Staniland, J.R., Lipkin, G.W. \& Turney, J.H. Acute renal failure: A study of elderly patients. Age Ageing 1990, 19: 36-42. be helpful along with cultures of blood and urine. Early referral to a renal unit is advised. Prompt diagnosis and treatment may avoid chronic renal failure in a group which has a poor outcome on long-term dialysis.

9. Stott, R.B., Cameron, J.S., Ogg, C.S. \& Bewick, M. Why the persistently high mortality in acute renal failure? Lancet 1972 , 2: $75-79$.

10. Lamiere, N., Matthys, E., Vanholder, R. et al. Causes and prognosis of acute renal failure in elderly patients. Nephrol Dial Transplant 1987, 2: 316-322.

11. Kumar, R., Hill, C.M. \& McGeown, M.G. Acute renal failure in the elderly. Lancet 1983, i: 90-91.

12. Oliveira, D.B.G. \& Winearls, C.G. Acute renal failure in the elderly can have a good prognosis. Age Ageing 1984, 13: 304-308.

13. Gleckman, R., Blagg, N., Hibert, D. et al. Acute pyelonephritis in the elderly. South Med J 1982, 75: 551-554.

14. McAlpine, C.H., Martin, B.J., Lennox, I.M. \& Roberts, M.A. Pyrexia in infection in the elderly. Age Ageing 1986, 15: 230-234.

15. Downton, J.H., Andrews, K. \& Puxty, J.A.H. 'Silent' pyrexia in the elderly. Age Ageing 1987, 16: 41-44.

16. Propper, D.J. \& Catto, G.R.D. Urinary tract infection in old age. Br J Hosp Med 1989, 42: 441. 